BIOFARM

Jurnal Ilmiah Pertanian

ISSN Print: 0216-5430; ISSN Online: 2301-6442

Vol. 15, No. 1, April 2019

\title{
Pengaruh Konsentrasi Rootone F Terhadap Pertumbuhan Stek Beberapa Klon Melati (Jasminum spp)
}

\author{
Influence of Rootone F Concentration on Cut Growth of Some Jusmin Clones \\ (Jusminum Spp)
}

\author{
Agung Gumelar ${ }^{1 *}$ dan Ari Handriatni ${ }^{1}$ \\ ${ }^{1}$ Program Studi Agroteknologi, Fakultas Pertanian, Universitas Pekalongan \\ *Korespondensi Penulis: Agungenci27@gmail.com
}

\begin{abstract}
ABSTRAK
Penelitian bertujuan untuk mengetahui pengaruh konsentrasi Rootone $\mathrm{F}$ terhadap pertumbuhan stek beberapa klon melati. Telah dilaksanakan di Desa Kulu Kecamatan Karanganyar, Kabupaten Pekalongan. Rancangan percobaan yang digunakan adalah rancangan kelompok (RAK) dengan an faktorial $4 \times 3$. Faktor pertama konsentrasi Rootone $F$ yang terdiri atas 4 taraf, yaitu 0 ppm, 1000 ppm, 3000 ppm, dan 5000 ppm. Faktor kedua macam klon melati yang terdiri dari Melati Putih, Melati Gambir, Melati Emprit. Variabel yang di amati dalam percobaan ini yaitu : Persentase stek hidup, Kecepatan muncul tunas, Tinggi tanaman per tanaman, Jumlah daun per tanaman, Panjang akar terpanjang per tanaman, Jumlah akar per tanaman, Bobot basah tanaman, Bobot kering tanaman, Bobot basah akar per tanaman dan Bobot kering akar per tanaman. Konsentrasi Rootone $F$ sangat berbeda nyata terhadap variabel kecepatan muncul tunas, tinggi tanaman pertanaman, panjang akar terpanjang, jumlah akar, bobot basah tanaman dan bobot kering tanaman. Konsentrasi Rootone $\mathrm{F}$ terbaik untuk pertumbuhan stek klon melati pada konsentrasi 3000 ppm (K2). Macam klon melati berbeda sangat nyata terhadap variabel kecepatan muncul tunas, tinggi tanaman pertanaman, panjang akar terpanjang, jumlah akar, bobot basah tanaman dan bobot kering tanaman. Macam klon terbaik adalah melati putih (M1).Terdapat interaksi antara konsentrasi Rootone $F$ dan macam stek klon melati berbeda sangat nyata terhadap bobot basah tanaman dan bobot kering tanaman, serta berbeda nyata terhadap variabel tinggi tanaman. Interaksi terbaik didapat pada pupuk konsentrasi Rootone $\mathrm{F}$ K2 $=3000 \mathrm{ppm}$ dan stek klon melati putih (K2M1).
\end{abstract}

Kata Kunci : Pengaruh Rootone F , beberapa klon melati.

\begin{abstract}
The aim of this research is to know the effect of Rootone $F$ concentration on the growth of cuttings of some clones of jasmine. It has been implemented in Kulu Village, Karanganyar Subdistrict, Pekalongan Regency. The experimental design used was group design (RAK) with $4 \times 3$ factorial treatment. The first factor concentration of Rootone $F$ consisting of 4 levels, namely $0 \mathrm{ppm}, 1000 \mathrm{ppm}, 3000 \mathrm{ppm}$, and $5000 \mathrm{ppm}$. The second factor is jasmine clone which consists of Jusminum sambac, jusminum officinale, and jusminum sambac orlaen. The variables observed in this experiment were: Percentage of live cuttings, Speed of appearance of buds, Plant height per plant, Number of leaves per plant, Longest root length per plant, Number of roots per plant, Wet weight of plant, Plant dry weight, Wet weight of root per plant and root dry weight per plant. Rootone $\mathrm{F}$ concentrations were significantly different from the variables of shoot pace, plant height, length of root length, root number, wet weight of plant and dry weight of plant. The best Rootone F concentration for the growth of jasmine clone cuttings at concentrations of $3000 \mathrm{ppm}$ (K2). Kinds of jasmine clones are very different from the variables of shoot pace, plant height, long root length, root number, plant wet weight and dry weight of plant. The best kind of clone is white jasmine (M1). There is an interaction between Rootone $\mathrm{F}$ concentration and different types of clone of jasmine clone significantly to the wet weight of plants and dry weight of plants, and significantly different to the plant height variables. The best interaction was obtained at concentration fertilizer Rootone $\mathrm{F} \mathrm{K2}=3000 \mathrm{ppm}$ and jasmine clone cuttings (K2M1)
\end{abstract}

Keywords: concentration Rootone F, several clones of jasmine.

\section{PENDAHULUAN}

Salahsatu tanaman hias yang berasal dari Asia, mempunyai karakteristik perdu, dengan tinggi bias mencapai 0,3-3 m, hidup liar, dijumpai banyak di Philipina, Asia Tenggara bahkan Indonesia adalah tanaman Melati.
Arsitektur tanaman melati, mulai dari akar, batang, dan bunga sangat bermanfaat, sehingga perlu dibudidayakan secara intensif. Budidaya melati mulai dari ketinggian 0 mdpl sampai datran tinggi dapat 
tumbuh dengan baik. Melihat banyaknya manfaat melati dan prospektif serta mempunyai nilai ekonomi tinggi, berwarna putih dan harum semerbak aromanya, maka pertumbuhan dan produksi perlu dikembangkan.

Kandungan minyal atsiri yang terdapat dalam bunga melati, dapat digunakan sebagai parfum, obat - obatan, pengharum the, sehingga bunganya berpotensi cukup besar dalam agroindustri. Kebutuhan untuk wilayah DKI Jakarta saja mencapai 1,5 - 2 ton setiap bulan, artinya kebutuhan lokalpun sangat tinggi. Penjual melati skala kecil pun belum terpenuhi rata - rata perhari $5-10 \mathrm{~kg}$ saja. Pada hari - hari besar umat muslim, perayaan keagamaan, upacara keagamaan, pernikahan, upacara pemakamanpun memerlukan melati dalam jumlah besar, selain untuk pewangi the, parfum, farmasi dan bunga tabor, peminatnya mengalamai lonjakan.

Menurut Rukmana (2003) produksi melati Indonesia baru memenuhi $20 \%$ nya saja dari kebutuhan masyarakat. Hal ini berpotensi untuk dikembangkan mengingat luasnya lahan dan agroklimatologi yang sesuai untuk budidaya melati. Perbanyakan melati dilakukan dengan stek, cangkok untuk mendapatkan kualitas bunga melati yang diharapkan konsumen (Wuryaningsih, 1997).

Faktor - factor yang mempengaruhi keberhasilan stek adalah factor tanaman induk sebagai bahan stek, pelaksanaan penyetekan dan faktor lingkungan seperti suhu, kelembaban, cahaya dan media tanam. Bunga melati mempunyai nilai ekonomi yang tinggi dan prospektif bahkan sudah export ke Singapur (Yusuf, 2007).

Hormon perakaran sintetis yang sering digunakan adalah indol-3 butirat (IBA) dan asam neptalen asetat (NAA) yang merupakan Rootone $\mathrm{F}$ dari golongan auksin. Rootone $\mathrm{F}$ tersebut di formulasikan untuk zat perangsang akar dengan nama dagang Rootone F (ashari, 1995). Dalam penelitian Haryana (2003), mengatakan bahwa Rootone F merupakan Rootone $F$ yang dapat mempercepat akar keluar sehingga unsur hara yang terdapat dalam media dapat diserap yang akibatnya dapat memacu pertumbuhan tunas.

Berdasarkan uraian tersebut maka perlu dilakukan penelitian Pengaruh Konsentrasi Rootone F Terhadap Pertumbuhan Stek Beberapa Klon Melati (Jasminum spp). Penelitian ini dilakukan dengan tujuan Untuk mengetahui konsentrasi Rootone $F$ yang optimal untuk meningkatkan pertumbuhan stek melati, mengetahui macam klon yang tepat, meningkatkan pertumbuhan stek melati dan untuk mengetahui interaksi antara konsentrasi Rootone $\mathrm{F}$ dan beberapa klon stek yang tepat untuk meningkatkan pertumbuhan stek melati.

\section{BAHAN DAN METODE}

Penelitian telah dilaksanakan dilaksanakan di Desa Kulu, Kecamatan Karang anyar, Kabupaten Pekalongan yang terletak pada ketinggian kurang lebih 110 meter diatas permukaan laut dengan jenis tanah latosol, percobaan mulai bulan Juli sampai dengan bulan September 2017.

Rancangan yang digunakan dalam penelitian ini adalah Rancangan Acak Kelompok (RAK), dengan 4 taraf konsentrasi dan 3 taraf jenis klon melati, faktor pertama adalah konsentrasi Rootone $\mathrm{F}$ yang terdiri atas tanpa Rootone $F(K 0), 1000$ ppm (K1) 3000 ppm (K2), 5000 ppm (K3). Faktor kedua adalah naungan yang terdiri atas stek melati putih (M1), Stek melati emprit (M2) dan stek melati gambir (M3). Masing-masing kombinasi diulang tiga kali dengan 12 kombinasi perlakuan sehingga seluruhnya ada 36 satuan percobaan. Satuan percobaan terdiri atas lima sampel tanaman sehingga seluruhnya ada $36 \times 5=180$ tanaman sampel.

Variabel yang diamati meliputi: Persentase stek hidup (\%), kecepatan saat muncul tunas, tinggi tanaman pertanaman, jumlah daun per tanaman, panjang akar terpanjang, jumlah akar pertanaman, bobot basah tanaman, bobot kering tanaman, bobot basah akar, bobot kering akar. Data 
dianalisis dengan analisis sidik ragam berdasarkan uji $\mathrm{F} 5 \%$ dan $1 \%$. Jika berpengaruh nyata dilanjutkan dengan uji BNT 5\%.

\section{HASIL DAN PEMBAHASAN Konsentrasi Rootone F}

Hasil penelitian menunjukkan konsentrasi Rootone $F$ berbeda sangat nyata terhadap variabel kecepatan kemunculan tunas, tinggi tanaman per tanaman, panjang akar terpanjang dan jumlah akar. Hasil analisa data menunjukan bahwa konsentrasi Rootone F tidak berbeda nyata terhadap persentase stek hidup. Hal ini disebabkan stek tumbuh pada lingkungan yang optimal, sehingga batang stek mempunyai kesempatan untuk tumbuh yang sama.

Tabel 1. Angka rata-rata dan Analisis Statistik Data Penelitian Pengaruh Konsentrasi Rootone $F$ Terhadap Pertumbuhan Stek Beberapa Klon Melati (Jasminum spp)

\begin{tabular}{|c|c|c|c|c|}
\hline Perlakuan & $\begin{array}{l}\text { Persentase stek } \\
\text { hidup (\%) }\end{array}$ & $\begin{array}{l}\text { Kecepatan } \\
\text { muncul tunas } \\
\text { (hari) }\end{array}$ & $\begin{array}{c}\text { Tinggi tanaman } \\
\text { per tanaman }(\mathrm{cm})\end{array}$ & $\begin{array}{l}\text { Jumlah daun } \\
\text { per tanaman } \\
\text { (helai) }\end{array}$ \\
\hline \multicolumn{5}{|l|}{ Konsentrasi Rootone F } \\
\hline K0 & 66,67 & $31,1 b c$ & $24,64 a$ & 3,91 \\
\hline K1 & 71,11 & $27,5 b$ & $32,34 \mathrm{c}$ & 4,09 \\
\hline K2 & 77,78 & $23,9 a$ & $35,12 d$ & 4,11 \\
\hline K3 & 73,33 & $28,9 b$ & $27,95 b$ & 3,98 \\
\hline \multicolumn{5}{|l|}{ Macam Klon } \\
\hline M1 & 75,00 & $25,88 a$ & $33,20 c$ & 3,93 \\
\hline M2 & 71,67 & $30,00 \mathrm{~b}$ & $27,43 a$ & 4,17 \\
\hline M3 & 70,00 & $27,63 a$ & $29,40 \mathrm{~b}$ & 3,97 \\
\hline
\end{tabular}

Menurut Rochiman dan Harjadi (1973) faktor lingkungan yang mempengaruhi perakaran dan pertumbuhan stek adalah media tanam, temperatur, cahaya dan kelembaban. Rootone F merupakan senyawa atau zat kimia yang pemberiannya harus sesuai dengan kebutuhan tanaman. Aplikasi ZPT Rootone $\mathrm{F}$ pada konsentrasi rendah, kurang efektif dalam melakukan perubahan proses fisiologis, baik pada proses pertumbuhan dan perkembangan tanaman, terutama tergantung pada jenis atau varietasnya.

Proses keberhasilan stek ditandai dengan terbentuknya akar terlebih dahulu baru terbentuk tunas, dimana akar dapat berperan untuk penyerapan air dan unsur hara (Mariska dkk., 1987), dapat menghasilkan Rootone $\mathrm{F}$ yang diperlukan untuk induksi tunas sehingga pemberian Rootone $\mathrm{F}$ dengan konsentrasi optimum mendukung pertumbuhan tunas yang kemudian berpengaruh terhadap kecepatan kemunculan tunas.

\section{Macam klon melati}

Hasil penelitian menunjukan bahwa macam klon berbeda sangat nyata terhadap kecepatan muncul tunas dan tinggi tanaman Rohiman dan Harjadi (1973) 
Tabel 2. Angka rata-rata dan Analisis Statistik Data Penelitian Pengaruh Konsentrasi Rootone F Terhadap Pertumbuhan Stek Beberapa Klon Melati (Jasminum spp)

\begin{tabular}{lcccccc}
\hline Perlakuan & $\begin{array}{c}\text { Panjang } \\
\text { akar } \\
\text { terpanjang } \\
\text { (cm) }\end{array}$ & $\begin{array}{c}\text { Jumlah } \\
\text { akar } \\
\text { (buah) }\end{array}$ & $\begin{array}{c}\text { Bobot basah } \\
\text { tanaman } \\
\text { (gram) }\end{array}$ & $\begin{array}{c}\text { Bobot kering } \\
\text { tanaman } \\
\text { (gram) }\end{array}$ & $\begin{array}{c}\text { Bobot } \\
\text { basah akar } \\
\text { (gram) }\end{array}$ & $\begin{array}{c}\text { Bobot kering akar } \\
\text { (gram) }\end{array}$ \\
\hline Konsentrasi Rootone F & $4,48 \mathrm{a}$ & $7,18 \mathrm{a}$ & $11,75 \mathrm{a}$ & $2,06 \mathrm{a}$ & 3,90 & 0,83 \\
K0 & $4,90 \mathrm{a}$ & $7,86 \mathrm{a}$ & $13,09 \mathrm{~b}$ & $2,54 \mathrm{c}$ & 4,03 & 0,90 \\
K1 & $5,91 \mathrm{~b}$ & $9,85 \mathrm{~b}$ & $16,23 \mathrm{c}$ & $2,90 \mathrm{~d}$ & 4,25 & 0,96 \\
K2 & $4,42 \mathrm{a}$ & $7,09 \mathrm{a}$ & $12,64 \mathrm{~b}$ & $2,34 \mathrm{~b}$ & 3,99 & 0,86 \\
K3 & & & & & & \\
Macam Klon & $5,62 \mathrm{c}$ & $9,13 \mathrm{c}$ & $15,84 \mathrm{c}$ & $2,90 \mathrm{c}$ & $4,37 \mathrm{~b}$ & $0,96 \mathrm{~b}$ \\
M1 & $4,22 \mathrm{a}$ & $6,85 \mathrm{a}$ & $11,79 \mathrm{a}$ & $2,16 \mathrm{a}$ & $3,73 \mathrm{a}$ & $0,82 \mathrm{a}$ \\
M2 & $4,94 \mathrm{~b}$ & $8,01 \mathrm{~b}$ & $12,65 \mathrm{~b}$ & $2,32 \mathrm{~b}$ & $4,03 \mathrm{ab}$ & $0,88 \mathrm{ab}$ \\
M3 & & &
\end{tabular}

Keterangan : Angka yang diikuti huruf yang sama pada kolom dan baris menunjukkan tidak berbeda nyata menurut uji BNT taraf $5 \%$

menyatakan bahwa yang mempengaruhi perkembangan tunas dan akar pada stek adalah sediaan karbohidrat dan nitrogen. Menurut Zulkarnain (2009), saat perkembangan jaringan primer terjadi pembentukan jaringan.

Berdasarkan hasil penelitian menunjukkan bahwa macam klon berbeda sangat nyata terhadap panjang akar terpanjang dan jumlah akar per tanaman. Panjang akar terpanjang dan jumlah akar tertinggi dicapai pada klon melati putih dengan panjang 5,6 (cm) dengan jumlah akar 9,1 (buah). Kondisi batang pada saat pengambilan yang terbaik adalah saat batang berwarna hijau kecoklatan. Rootone-F mengandung IBA dan NAA yang berfungsi sebagai stimulator pembelahan sel sehingga lebih memungkinkan terbentuknya sistem perakaran lebih baik (Arinasa, 2015)

Abidin (1990) menyatakan proses terbentuknya akar apabila karbohidrat, auksin, nitrogen dan rooting cofactor (zat yang berinteraksi dengan auksin yang menyebabkan perakaran) pada klon dalam keadaan seimbang sehingga mampu meningkatkan jumlah akar. auksin yang menyebabkan perakaran) pada klon dalam keadaan seimbang sehingga mampu meningkatkan jumlah akar. Proses pembentukan akar pada stek batang biasanya dimulai dengan pembentukan kalus yang merupakan tahap awal dari inisiasi akar.

Berdasarkan hasil penelitian menunjukan bahwa macam klon berbeda sangat nyata terhadap bobot basah tanaman dan dan bobot kering tanaman. Bobot basah dan bobot kering tanaman yang terbaik dicapai oleh klon melati putih dengan bobot basah tanaman 4,37 (gram), dan bobot kering tanaman 2,9 (gram) Perbedaan ini diakibatkan adanya perbedaan fenotip dari masing-masing klon.

Menurut Simatupang (1997), menyatakan klon dapat beradaptasi dengan lingkungannya maka produksi tinggi. Gardner dkk. (1991) menyatakan factor internal perangsang pertumbuhan tanaman berada dalam kendali genetik, meningkatnya pertumbuhan tanaman seperti akar dan batang akan mempengaruhi peningkatan laju proses fotosintesis sehingga asimilat yang dihasilkan juga bertambah banyak, selanjutnya asimilat tersebut ditranslokasikan dan diakumulasikan pada bagian tanaman. $\mathrm{Hal}$ ini berpengaruh pada bertambahnya bobot basah dan bobot kering tanaman.

Berdasarkan hasil penelitian menunjukan bahwa macam klon berbeda nyata terhadap bobot basah akar dan bobot kering akar per tanaman. Berdasar kan hasil penelitian menunjukan bahwa macam klon berbeda nyata terhadap bobot basah akar dan bobot kering akar per tanaman. Menurut Harjadi (1991) meningkatnya pertumbuhan vegetatif tanaman akan berpengaruh terhadap meningkatnya serapan unsur hara, air oleh tanaman, maka laju fotosintetis tanaman juga meningkat sehingga fotosintat yang dihasilkan juga menjadi lebih banyak. 


\section{Interaksi konsentrasi Rootone F dan macam klon}

Terdapat interaksi antara konsentrasi

Rootone $\mathrm{F}$ dan macam klon berbeda nyata terhadap tinggi tanaman per tanaman. Menurut Lakitan (1996) bahwa hormon auksin disintesis pada pucuk-pucuk titik tumbuh tunas, sehingga meningkatnya per-

Tabel 3. Angka rata-rata Interaksi Pengaruh Konsentrasi Rootone F Terhadap Pertumbuhan Stek Beberapa Klon Melati (Jasminum spp)

\begin{tabular}{cccc}
\hline Perlakuan & $\begin{array}{c}\text { Tinggi tanaman per } \\
\text { tanaman }(\mathrm{cm})\end{array}$ & $\begin{array}{c}\text { Bobot basah tanaman } \\
(\text { gram })\end{array}$ & $\begin{array}{c}\text { Bobot kering tanaman } \\
(\text { gram })\end{array}$ \\
\hline K0M1 & $25,78 \mathrm{bc}$ & $13,46 \mathrm{e}$ & $2,35 \mathrm{e}$ \\
K0M2 & $23,15 \mathrm{a}$ & $9,91 \mathrm{a}$ & $1,73 \mathrm{a}$ \\
K0M3 & $24,98 \mathrm{~b}$ & $11,87 \mathrm{c}$ & $2,08 \mathrm{~b}$ \\
K1M1 & $35,56 \mathrm{i}$ & $15,19 \mathrm{~g}$ & $2,94 \mathrm{i}$ \\
K1M2 & $29,55 \mathrm{f}$ & $11,67 \mathrm{bc}$ & $2,26 \mathrm{~d}$ \\
K1M3 & $31,92 \mathrm{~h}$ & $12,42 \mathrm{~d}$ & $2,41 \mathrm{f}$ \\
K2M1 & $42,15 \mathrm{j}$ & $20,43 \mathrm{~h}$ & $3,65 \mathrm{j}$ \\
K2M2 & $30,79 \mathrm{~g}$ & $14,12 \mathrm{f}$ & $2,53 \mathrm{~g}$ \\
K2M3 & $32,42 \mathrm{~h}$ & $14,13 \mathrm{f}$ & $2,53 \mathrm{~g}$ \\
K3M1 & $29,32 \mathrm{ef}$ & $14,29 \mathrm{f}$ & $2,64 \mathrm{~h}$ \\
K3M2 & $26,22 \mathrm{c}$ & $11,46 \mathrm{~b}$ & $2,12 \mathrm{~b}$ \\
K3M3 & $28,29 \mathrm{e}$ & $12,18 \mathrm{~d}$ & $2,25 \mathrm{c}$ \\
\hline
\end{tabular}

Keterangan : Angka yang diikuti huruf yang sama pada kolom dan baris menunjukkan tidak berbeda nyata menurut uji BNT taraf $5 \%$

tumbuhan tanaman akan meningkatkan sintesis auksin yang selanjutnya ditransportasikan secara polar basipetal, yaitu dari ujung ke pangkal seperti pada tunas-tunas, kemudian sel-sel tanaman akan mengalami pembelahan, kondisi ini didukung dengan penggunaan klon melati putih yang memiliki jumlah cadangan makanan. Sesuai dengan pendapat Rohiman dan Harjadi (1973) menyatakan bahwa kandungan makanan stek, terutama sediaan karbohidrat dan nitrogen sangat mempengaruhi perkembangan akar dan tunas pada stek. Terdapat interaksi antara konsentrasi Rootone $\mathrm{F}$ dan macam klon berbeda sangat nyata terhadap bobot basah dan bobot kering tanaman.

Salisbury dan Ross (1995) menyatakan bahwa bobot basah tanaman menunjukkan aktivitas metabolisme tanaman dan nilai bobot basah dipengaruhi oleh kadar air tinggi. Sesuai pendapat Simatupang (1997) yang menyatakan bahwa tingginya produksi suatu varietas dikarenakan klon tersebut mampu beradaptasi dengan lingkungannya.

Gardner dkk. (1991) menyatakan bahwa faktor internal perangsang pertumbuhan tanaman berada dalam kendali genetik, meningkatnya pertumbuhan tanaman seperti akar dan batang akan mempengaruhi peningkatan laju proses fotosintesis tanaman sehingga hasil fotosintesis berupa asimilat yang dihasilkan juga bertambah banyak.

\section{SIMPULAN}

Berdasarkan hasil penelitian dapat disimpulkan sebagai berikut :

1. Konsentrasi Rotoone $F$ sangat berbeda nyata terhadap variabel kecepatan muncul tunas, tinggi tanaman pertanaman, panjang akar terpanjang, jumlah akar, bobot basah tanaman dan bobot kering tanaman. Konsentrasi Rootone $\mathrm{F}$ terbaik untuk pertumbuhan stek klon melati pada konsentrasi 3000 ppm (K2).

2. Macam klon melati berbeda sangat nyata terhadap variabel kecepatan muncul tunas, tinggi tanaman pertanaman, panjang akar terpanjang, jumlah akar, bobot basah tanaman dan bobot kering tanaman., serta tidak berbeda nyata terhadap bobot basah akar dan bobot kering 
akar. Macam klon terbaik adalah melati putih(M1).

3. Terdapat interaksi antara konsentrasi Rootone $\mathrm{F}$ dan macam stek klon melati berbeda sangat nyata terhadap bobot basah tanaman dan bobot kering tanaman, serta berbeda nyata terhadap variabel tinggi tanaman. Interaksi terbaik didapat pada pupuk konsentrasi Rootone $\mathrm{F}$ $\mathrm{K} 2=3000 \mathrm{ppm}$ dan stek klon melati putih (K2M1).

\section{DAFTAR PUSTAKA}

Abidin, Z. 1990. Dasar-Dasar Pengetahuan tentang Zat Pengatur Tumbuh. Penerbit Angkasa, Bandung. 85 hal.

Arinasa. 2015. Pengaruh Konsentrasi Rootone-F dan Panjang Setek pada Pertumbuhan Begonia tuberosa Lmk. J. Hort. 25(2):142-149

Gardner FP, RB Pearce and RL Mitchell. 1991. Fisiologi Tanaman Budidaya. UI Press, Jakarta.

Harjadi, M. M. S. S, 1991. Pengantar Angronomi. Gramedia Pustaka Utama. Jakarta. $172 \mathrm{hlm}$

Lakitan. B. 1996. Fisiologi Pertumbuhan dan Perkembangan Tanaman. Rajawali Press. Jakarta.

Mariska, L., I. Darwati, dan H. Moko. 1987. Perbanyakan stek Panili (Vanilla planifolia) dengan Rootone $F$ pada berbagai media tumbuh.
Laporan Penelitian Perbanyakan Tanaman Pada Media Tumbuh Pelet Jiffy. Balai Penelitian Perkebunan, Bogor.

Rochiman, K. \& S.S. Harjadi., 1973. Pembiakan vegetatif. Bogor: Fakultas Pertanian. IPB.

Rukmana R., 2003. Usaha Tani Melati. Kanisius. Yogyakarta

Salisbury F.B. dan C.W. Ross. 1995. Plant Physiology 3rd Ed. California : Wardworth Publishing Company Belmont. Hal : $309-349$

Setyawati ER. 2011. Studi Respon Pertumbuhan Stek Nilam (Pogostemon cablin Benth) terhadap Nomor Ruas Bahan Stek dan Konsentrasi Rhizzatun F. J. Pertanian 2 (2) 95-102

Simatupang, S. 1997. Pengaruh Pemupukan Boraks Terhadap Pertumbuhan dan Mutu Tanaman Sayuran. J. Hortikultura 6 (5) : 456-569

Wuryaningsih, S. 1997. Pengaruh media tanam dan bahan stek terhadap pertumbuhan stek melati. Laporan Penelitian. 10 hal. Tidak dipublikasi

Zulkarnain. 2009. Kultur Jaringan: Solusi Perbanyakan Tanaman Budidaya. Jakarta (ID): Bumi Aksara. 